\title{
Costing the lifecycle of networked learning: documenting the costs from conception to evaluation
}

\author{
Paul Bacsich and Charlotte Ash \\ School of Computing and Management Services, Sheffield Hallam University \\ email:p.bacsich@shu.ac.uk
}

This paper reports the development of a course development lifecycle model which is intended to inform the identification of 'hidden' costs associated with network-based learning. The development of this model formed part of a six-month research study funded by the Joint Information Systems Committee of the UK Funding Councils. The study aimed to produce a planning document and financial schema through which the full costs of networked learning could be documented. A discussion is given of the initial fivestage model, the testing and development of this model and the evolution of a final three-phase model. Hypothetical examples are given of the use of the three-phase model.

\section{Introduction}

Analysing the costs of new learning technologies within the educational sector is currently a neglected area, yet the issue of how to spend money effectively in this context is a question that must be answered. This question is made especially pertinent with the current expansion of information technology into higher and further education. To know the costeffectiveness of these initiatives, it is first necessary to gain some comprehension of the costs involved. This must be done in a way that is comprehensible to everyone in academia. A recently completed research study undertaken by the authors addressed these problems.

The study, entitled Costs of Networked Learning (http://www.shu.ac.uk/virtual_campus/ $\mathrm{cnl} /$ ), was funded by the Joint Information Systems Committee of the UK Funding Councils (JISC). It ran over a six-month period (January to June 1999) based at Sheffield Hallam University. The main aims of the study were to identify the unrecorded or hidden costs involved in networked learning and to produce a planning document and financial schema to aid the development of networked learning activities. A lifecycle model was 
developed as a key component of the financial schema, in that it guides the user to document particular costs at particular stages of development. This paper describes the development of this lifecycle model.

Networked learning is taken to be synonymous with 'online learning' and 'technology enhanced learning'. Hidden costs are costs which appear somewhere in financial accounts but are either unrecorded by the institution, such as personally incurred costs by staff or students, or absorbed into larger budgets without being attributed to an individual activity or process. Examples of hidden costs include:

- increased telephone call bills for students due to Internet use to access lecture notes, course conferencing and assignments;

- expenses incurred by academic staff at conferences which are not reimbursed by the institution;

- use of research funds to bolster teaching resources - or vice versa.

A wider definition of hidden costs includes such 'costs' as 'opportunity costs' - costs of staff who could be deployed in a way different from their current use (for example, academic staff who could carry out commercial-fee postgraduate teaching rather than undergraduate work). Our planning work in the study goes into this area when it considers alternative options and risk analysis; it also to an extent looks at non-financial choice factors. However, such topics are not central to this paper.

The study is intended to inform the decisions made by institutional policy-makers and course providers planning networked learning initiatives. The outcomes of the study (the lifecycle model, planning document and financial schema) should be relevant to the needs of policy makers, managers, course providers and administrators. The model should be easily understandable by all these professionals. Hence, the lifecycle framework is strongly grounded on what the people in academia are familiar with.

The paper describes the initial five-stage model based on an analysis of a literature review conducted during the early stages of the project, the testing and development of this model, and the evolution of the final model. The application of the model is illustrated in the context of two hypothetical scenarios.

\section{The initial model}

The study team conducted an extensive literature review during the first phase of the project. The aim of the review was twofold. Firstly, the team's understanding of the 'costing of learning' (including distance learning and networked learning) was updated and extended. Secondly, 'cost items' mentioned by other authors were extracted. Over 100 cost items were identified during the project, many of which do not usually exist as university cost codes. These can therefore be regarded as hidden costs, which are normally subsumed into other, possibly unrelated, budgets. Examples of these include course-related access to the Internet, creative design of materials, evaluation of bought-in materials, and the rollout of specialist software.

Part of the project brief was to build a framework within which all of these cost items could be documented. Therefore the team analysed currently available models that attempt 
to provide a framework for recording the costs of technology-enhanced learning systems. There were initial concerns about the value of traditional institutional financial management accounting procedures for exposing the full range of the hidden costs. Traditional methods typically do not provide detailed costs, especially with respect to central departments. In addition costs are usually expressed in departmental terms, rather than project or activity terms. Despite these reservations, three traditional accounting insights were useful:

- Distinct organizations have separate budgets; in particular, university-borne costs are distinct from student-borne costs.

- There are fundamental accounting distinctions between people and things - between staff and non-staff - and between capital and recurrent costs.

- Organizations employ different kinds of people; specifically, in universities there are academic and non-academic staff.

In addition, one modern insight is fundamental:

- People do different kinds of tasks and the balance of their tasks changes even within the accounting period - this is the basis of activity-based costing (ABC).

Using these four basic insights, the team embarked on an analysis of the educational costing literature, concentrating upon their classification of costs. A summary of this review follows.

A categorization of costs associated with educational media which mixes activities with standard accounting categories is given by Orivel (1987): administration costs, production costs, diffusion costs and reception centres. Rumble (1989) believes costs can be classified as human resource costs; costs of developing, producing and delivering; capital equipment costs; consumables and expenses; and space and accommodation costs. This blurs the boundaries between staff and non-staff costs, and between capital and recurrent costs. It seems that Rumble is addressing the issue from a university planning perspective rather than taking a university accounting viewpoint. Cukier (1997) follows in similar vein to Rumble by categorizing the costs of educational technology as human resources, general administration, development; production and delivery, capital equipment and start-up, consumables and expenses and space and accommodation. This appears to mix fixed costs with variable costs, and capital costs with recurring costs.

Crabb (1990) and Moonen (1997) propose phase-related descriptions of cost categories. Moonen (1997) summarizes costs as personnel costs, equipment costs, facilities costs, material costs and other costs. These are calculated in a 'costs per activity phase' breakdown of a development phase and a delivery, operation and maintenance phase. Moonen has clearly separated costs into terms understandable to finance administrators and has also produced a lifecycle model. However, it is clear from a more detailed reading that he is considering the lifecycle of the course, not that of its supporting infrastructure. Two stages of development and delivery are used by Crabb, leading to categories of human resources, premises-related costs, equipment, consumables and expenses, central resources, and overheads. Although there are still deficiencies in light of the specific areas the study 
was addressing (such as evaluation), Crabb presents a coherent accounting framework which can be developed further.

The approaches analysed in the literature review were not strong in their ability to identify hidden costs. All suffered from one or more of the following weaknesses:

- Students are not considered either in terms of their income or of their expenditure.

- Staff are not considered, except as employees of the institution.

- Courses grow from nowhere and vanish into oblivion - the models on the whole do not take planning, evaluation and maintenance into account.

- There is no obvious connection between a learning module and the environment in which it is studied.

It was concluded that existing models were implausible in terms of documenting hidden costs and/or unsuited to the UK higher education sector. Therefore, a number of short consultative meetings were held with selected academics at the Sheffield Hallam University to discuss the lifecycle of course development and delivery and the issue of hidden costs. Based on these discussions, the varying experience of the study team in different areas, and the desire to illustrate the relationship between people and activities and therefore expose possible areas of hidden costs, a new 'five-phase, three stakeholder' working model was created. This is shown in Figure 1.

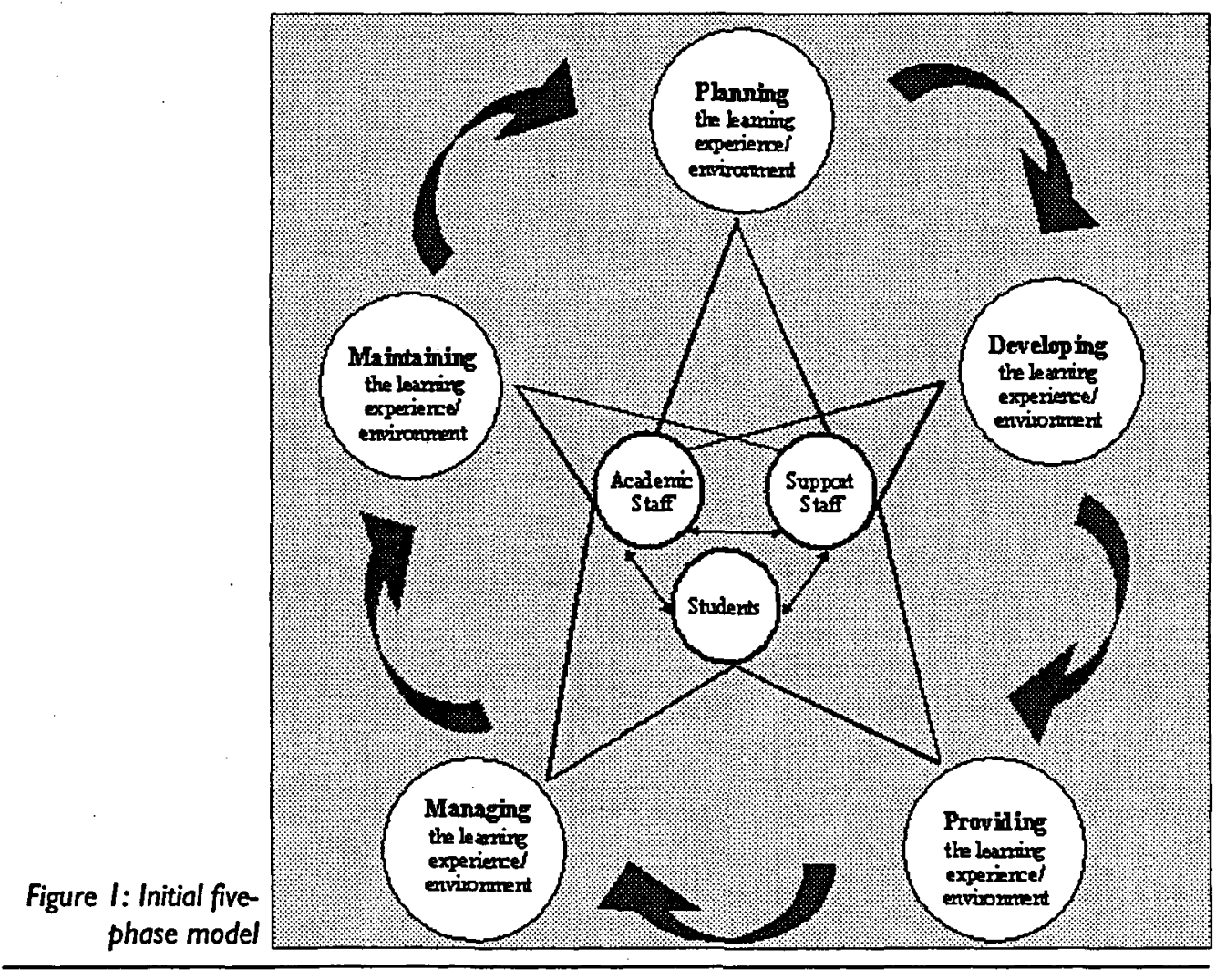


Figure 1 shows the five phases each lifecycle passes through: from initial planning, through developing, providing, managing, and maintaining; to further planning and on again through the cycle (as illustrated by the large arrows). The three groups of stakeholders academic staff, support staff and students - are influenced by other stakeholders (as shown by the small arrows); and different stakeholders are involved at different stages of the process (as represented by the lines forming a pentagon).

\section{Testing and development}

The five-phase model was subjected to a two-stage testing process. In the first stage, participants at interviews conducted during seven institutional case studies (see later for more details) were questioned about various aspects of the model. In the second stage, a small workshop was held to instigate discussion between a number of experts in the area (both in costing and in online learning), from the educational and the industrial training sectors. The purpose of such thorough testing was to assess the viability of the model in a sector where it is commonly accepted that staff are antipathetic to imposed methods of working. The model needs to resonate with academic working reality rather than impose an impractical strait-jacket.

\section{Test group one}

One of the main components of the study was to assess the extent of networked learning in UK higher education institutions by examining how these activities were costed, if at all. Seven institutions were selected (on the basis of their replies to a sector-wide survey) to represent the sector, using such criteria as research or teaching bias, geographical split and current status of networked learning activities. Teams of interviewers visited the institutions over a two-day period and interviewed academics, administrators and senior management, often receiving an additional tour of the facilities and activities taking place. Over fifty interviewees were shown a copy of the working model and asked to comment on several aspects.

Generally, the response to the working model was positive. Staff were pleased to see course maintenance and support staff being properly recognized in an educational setting. The 'lifecycle' approach to the issue was also commended. One interviewee expressed the view that simple methods have more impact on non-financially aware academics; however, another considered that even in its simplest form, the model would.need serious staff training and 'hearts and minds buy-in' at a grass-roots level in order to succeed.

However, there were some reservations. Staff in institutions thought that representation from senior management (deans and above) and evaluation should be included in the working model. Others thought that more general issues, such as flexibility and sustainability, should be included. Still others believed that additional stakeholders, such as employers and parents, should be incorporated. Some of the academic staff interviewed were concerned that any framework of this nature may be too rigid, since organizational change is slower than the pace of technology. Others believed that scenarios would be a good way of illustrating its function. Further analysis revealed that most academics were negative about the idea of a framework to document the costs of networked learning, while senior management were in favour of a framework that would help record the costs of any learning system. Much concern was expressed about whether such a model would stifle creativity and innovation, thus hindering the development of networked learning. 


\section{Test group two}

In addition to the case study interviews, a workshop was held at Sheffield Hallam University attended by several prominent educators and financial experts. The aims of the workshop were to facilitate discussion on costing networked learning and to explore ideas that would assist the study team in developing the project outcomes.

The experts agreed that the model should be equally appropriate for costing conventional teaching systems and for costing networked learning. If the model were not applicable to alternative systems, fair comparisons could not be made. This would leave the sector no closer to determining whether, and in what circumstances, networked learning is more costeffective than conventional teaching and learning. Relative costing was agreed to be more important than the issue of whether networked learning costs less in absolute terms.

Some omissions in the model were identified. Strategic planning was noted to be missing, but on discussion it was agreed that this should take place outside the existing model. Quality assurance and evaluation were also noted to be missing. Given the importance placed on these within the current academic climate, it was decided that these two aspects needed to be included in the model.

Further discussion on the model revealed that the industry-based experts were not comfortable with the five-phase working model. They proposed a four-phase model that 'helically' revolved through the following four phases: develop, market, provide and assure. However, the education-based experts were confident that universities would not accept the terminology and approach of the four-phase model and they also expressed worries that at least one of the categories (assure) was too 'sparse' in its suggested meaning to justify its own phase.

\section{The final model}

Both test groups noted that there were a number of omissions from the working model; these included evaluation, quality assurance and strategic planning. Another vital finding to arise from this testing process was that simple methods have more resonance with academic staff, especially when they impact on costs, time and workload. The team decided to accept the view that the original five-phase model was too complex, but to reject the four-phase business-derived model as unsuitable for documenting the hidden costs of networked learning within higher education. So, with the aim of combining simplicity with suitably headed categories, a new three-phase model was proposed.

The new model includes evaluation and quality assurance but assumes that strategic planning takes place on the periphery. Staff and students have been removed from the model, since it was decided, after much research and discussion with colleagues, that their place is secure now that the stakeholder analysis approach is becoming more accepted in educational circles. It should be noted at this stage that even though the learning environment is no longer specifically stated, this model also works on this level. The threephase model is shown in Figure 2. The three-phase model follows classic course planning frameworks from the distance education sector but also incorporates the increasingly accepted need for quality assurance and course maintenance. 


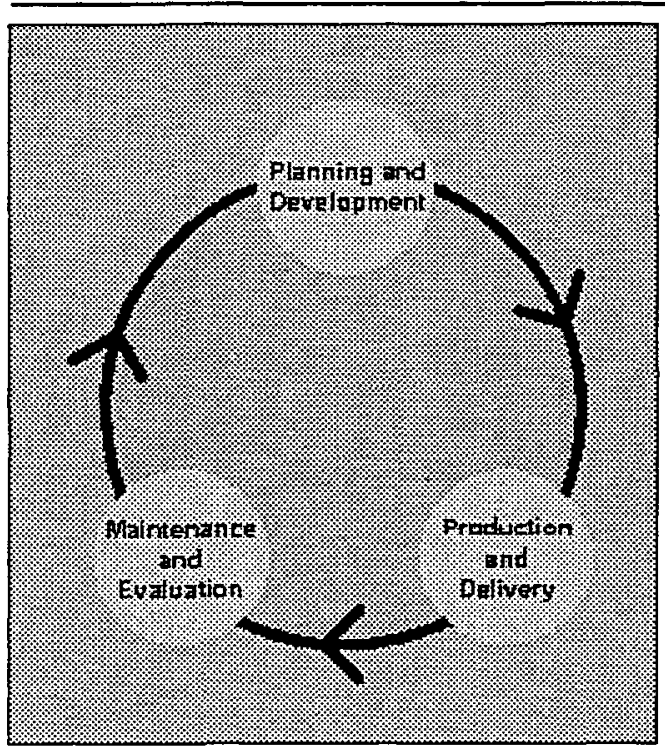

Figure 2: Three-phase model

The evolution from the five-phase to the three-phase model is shown in Table 1. Note that cells in the same row do not necessarily cover an identical set of sub-activities. This is especially true of the four-phase model.

\begin{tabular}{lll}
\hline Five-phase model & Four-phase model & Three-phase model \\
\hline Planning & (implicit?) & Planning ... \\
Developing & Develop & $\ldots$ and Development \\
Providing & Provide & Production and delivery ... \\
Managing & Market & $\ldots$ (includes managing and marketing) \\
Maintaining & Assure & Maintenance and evaluation \\
\hline
\end{tabular}

Table 1: Evolution of the lifecycle model from five to three phases.

The three-phase model was reviewed with respect to the major models identified in the initial literature review. Table 2 summarizes the review of the three-phase mòdel.

\begin{tabular}{lllll}
\hline Standard & Rumble (1997) & Moonen & Stahmer & Hunt and Clark \\
\hline $\begin{array}{l}\text { Planning and } \\
\text { development }\end{array}$ & $\begin{array}{l}\text { Production including } \\
\text { development }\end{array}$ & Development & $\begin{array}{l}\text { Research and } \\
\text { planning } \\
\text { development }\end{array}$ & $\begin{array}{l}\text { Research and } \\
\text { development } \\
\text { initial investment }\end{array}$ \\
$\begin{array}{l}\text { Production and } \\
\text { delivery }\end{array}$ & $\begin{array}{l}\text { Transmission and } \\
\text { distribution reception }\end{array}$ & $\begin{array}{l}\text { Production, delivery, } \\
\text { operation... }\end{array}$ & Delivery & $\begin{array}{l}\text { Operation and } \\
\text { support }\end{array}$ \\
$\begin{array}{l}\text { Maintenance and } \\
\text { evaluation }\end{array}$ & (omitted) & f.. and maintenance & (omitted) & Disposal and salvage \\
\hline
\end{tabular}

Table 2: A review of the three-phose model with respect to other models documented in the literature. 
Rumble (1997) defines costs as production costs (including development/conception); transmission or distribution costs (including duplication); and reception costs (including teaching costs and costs incurred by the student). Thus, he includes the costs incurred by academic staff and students. Moonen (1997) distinguishes two phases: a development phase and a production, delivery, operation and maintenance phase. We split his phase two into two parts, leaving maintenance in the third phase.

It became apparent in the later stages of our study project that work on costing in the training sector was closely related to the $\mathrm{ABC}$ systems we were working towards. However, although workers in this sector were more in touch with both the costs incurred by staff and students and the growing opportunity cost of activities, their models proved no more comprehensive than those above. Stahmer (1995) proposes a model of course development comprising three phases: research and planning; development; and delivery. In this instance, we group the first two together in our planning and development phase. Hunt and Clarke (1997) have a four-phase model: research and development; initial investment; operation and support; and disposal and salvage. Again, we group phases one and two together. Phase four is rather odd, and hard at first sight to equate with our maintenance and evaluation. One could assume that they were thinking of courses delivered primarily by CD-ROM.

It is noteworthy that evaluation is not generally considered when the costing of a learning environment is undertaken. The other main issue is one of terminology: there is no consensus across the board about the vocabulary one should use and no consistency in its use. It is hoped that once a suitable model is agreed upon, developments should become easier to plan and execute. Table 3 shows some of the sub-activities in each phase of the three-phase model.

\begin{tabular}{|c|c|}
\hline $\begin{array}{l}\text { Planning } \\
\text { and } \\
\text { Development }\end{array}$ & $\begin{array}{l}\text { collecting and buying-in material } \\
\text { developing text and multi-media material } \\
\text { writing user guides, course publicity, etc }\end{array}$ \\
\hline $\begin{array}{l}\text { Production } \\
\text { and } \\
\text { Delivery }\end{array}$ & $\begin{array}{l}\text { duplication of materials } \\
\text { teaching of the curriculum (face to face or online) } \\
\text { continuous assessment and final exam }\end{array}$ \\
\hline $\begin{array}{l}\text { Evaluation } \\
\text { and } \\
\text { Maintenance }\end{array}$ & $\begin{array}{l}\text { quality assurance procedures } \\
\text { replacement and updating of materials } \\
\text { educational evaluation against course aims }\end{array}$ \\
\hline
\end{tabular}

Table 3: Breakdown of the three-phase model.

\section{Hypothetical models of the use of the three-phase model}

The application of the three-phase model is illustrated with reference to two hypothetical examples. Given the fictitious nature of the examples, the model is only used to identify activities that will have hidden costs associated with them. No attempt is made to give precise costs associated with these activities. 
The first example is a 'conventional course':

Dr Albrecht of the University of Tynebridge was asked to teach a new final year course on post-deconstructionism this academic year for one semester. It followed the standard form in his institution of a one-hour lecture and one-hour discussion group each week. His lecture notes consisted of a topic list and a list of readings. The discussion group was moderated in a lightweight way by him and needed little preparation. He had to mark two essays per student during the course. The class size was fifteen.

Table 4 illustrates the application of the model:

\begin{tabular}{ll}
\hline Phase & Types of task \\
\hline Planning and development & $\begin{array}{l}\text { Read the latest works on the topic, listen to a new radio series, create lecture } \\
\text { notes (in Word), set essay topics. Adapt his own research articles to be suitable } \\
\text { to final-year students. } \\
\text { Give lectures, get lecture notes copied, moderate discussion groups, mark } \\
\text { Production and delivery }\end{array}$ \\
Maintenance and evaluation & $\begin{array}{l}\text { Students complained about his handwriting - so he will have to use OHPs } \\
\text { next year. He has heard that OU is putting on a similar course - perhaps he } \\
\text { could use the videos? RAE pressures mean that he would like to get his RA to } \\
\text { work as a TA to moderate the discussions. A particularly bright disabled } \\
\text { student has asked to attend next year's course 'online' - what to do? }\end{array}$ \\
\hline
\end{tabular}

Table 4: Application of the three-phase model to a 'conventional' course.

The second example is an online course:

Sensing a gap in the market, now that many arts graduates (e.g. at the BBC) have PCs and are on the Internet, Dr Carter at the University of Rother Bridge has approval to mount a totally online course on post-deconstructionism. This will be part of her new distance learning MA on 'radical philosophies'.

\begin{tabular}{ll}
\hline Phase & Types of task \\
\hline Planning and development & $\begin{array}{l}\text { Read the latest works on the topic, listen to a new radio series, create lecture } \\
\text { notes, set essay topics. Adapt her own research articles on 'deconstructing } \\
\text { gender - where next?' to be suitable to final year students. Put all this on the } \\
\text { course Web site. } \\
\text { Ask the computing service to set up a bulletin board system. (They want to } \\
\text { charge for doing this. She refuses, citing the departmental overhead.) } \\
\text { Make more material available on Web, such as topical items on philosophy, } \\
\text { Production and delivery } \\
\text { moderate discussion groups online, receive and mark essays sent in by email. } \\
\text { Set up 'real' office hours for those students who live nearby. }\end{array}$ \\
$\begin{array}{l}\text { Maintenance and evaluation } \\
\text { Students want some 'synchronous' online events; so must get technician to find } \\
\text { out about RealAudio and record some lectures for next year. Also worried } \\
\text { about the new OU global course in this area; how can she differentiate her } \\
\text { course? (What about her students at the BBC?) Can she write something } \\
\text { about this in a journal and count it for the next RAE? }\end{array}$
\end{tabular}

Table 5: Application of the threephase model to an online course. 


\section{Discussion}

All the problems are not solved with the three-phase model. An attempt has been made to ensure that all aspects of a course depending overtly and substantially on student numbers are mapped into the production and delivery phase. This includes assessment. We note the argument that assessment is not part of the 'teaching' of a course (and indeed in some workplanning models used in institutions, time for assessment is not explicitly counted). However there is a counter-argument that assessment (or at least formative assessment) is part of the teaching (or at least of learning in new paradigms), and that is the view adopted in this paper.

The lifecycle model was developed to assist institutions that do not have their own model but would like to use a model within the context of our proposed planning document and financial schema. In the wider context, the difficulties in developing a 'standard' model illustrate the lack of consensus in the sector about the best way to pursue course development. Adequate costing throughout the course lifecycle, and realistic attribution of overhead costs, are needed in universities today to inform resource-planning decisions and aid the effective management of organizational change.

The second phase of the Costs of Networked Learning Project will involve developing the current framework into a practical handbook featuring real or 'realistic' cost examples. A number of contentious issues raised by the study but outside the scope of this paper - such as the division of academic time and the recording of time - will be further investigated through workshops and discussions. It is hoped in time to widen the scope of the study area within education to include effectiveness, business models and the real cost of information technology in general (not just for teaching and learning). In this way, it is hoped that the cost-effectiveness of both traditional learning paradigms as well as new learning technologies within the educational sector will be better understood. This will allow comparisons to be made between old and new approaches towards teaching and learning, and will therefore enable the higher and further educational sectors to make more informed decisions.

\section{Acknowledgements}

The views expressed in this paper are those of the authors and the study team, who wish to acknowledge the support of the JISC and Sheffield Hallam University.

\section{References}

Crabb, G. (ed.) (1990), Costing Open and Flexible Learning, NCET: Coventry (UK).

Cukier, J (1997), 'Cost-benefit analysis of telelearning: developing a methodology framework', Distance Education, 18 (1), 137-52.

Hunt, M. and Clarke, A. (1997), A Guide to the Cost Effectiveness of Technology-Based Training, NCET: Coventry.

Moonen, J. (1997), 'The efficiency of telelearning', Journal of Asynchronous Learning Networks, 1 (2), http://www.aln.org/alnweb/journal/issue2/moonen.htm.

Orivel, F. (1987), Analysing Costs in Distance Education Systems: A Methodological Approach, IREDU, Dijon: Université de Bourgogne. 
Rumble, G. (1989), 'Online costs: interactivity at a price', in Mason, R. and Kaye, A. (eds), Mindweave: Communication, Computers and Distance Education, Oxford: Pergamon Press, 146-65.

Rumble, G. (1997), The Costs and Economics of Open and Distance Learning, London: Kogan Page.

Stahmer, A. (1995), Assessing Costs, Benefits, and Return on Investment for Technologybased Training: Tools for Decision Makers, Paper presented at Online Educa Berlin, 1st International Conference on Technology Supported Learning. 